Brit. F. industr. Med., 1966, 23, 149

\title{
Millworkers' Asthma: Allergic Responses to the Grain Weevil (Sitophilus granarius)
}

\author{
J. A. LUNN \\ From the Slough Industrial Health Service, Slough, Bucks
}

Two laboratory workers, who spent a considerable time each day handling grain infested by the grain weevil (Sitophilus granarius), developed allergic responses to this insect varying from rhinitis and pruritus to marked asthma. These findings suggested that weevil protein present in mill dust could result in sensitization in those exposed continuously. A pilot study was therefore undertaken on 75 volunteer millworkers to determine whether such sensitivity existed. A millworker was defined as anyone who worked in a flour mill or mill producing animal feed from mixed cereals, or who worked in grain-storing silos.

Skin testing with weevil, mixed flour extracts, and a control was carried out on all 75 volunteers; $57 \%$ had a positive response to the weevil extract and $68 \%$ a positive response to the mixed flour extract. In a control group of 100 workers from two engineering firms matched for age and sex, $34 \%$ were positive to the weevil extract and $17 \%$ to mixed flour.

From the initial 75 millworkers, I 5 were selected for further study based on a positive skin response to the weevil and a history of a productive cough and chest tightness and wheezing when exposed to mill dust. The forced expiratory volume in one second (F.E.V.1.0) was measured after control inhalations and after weevil and mixed flour inhalations. Significant reductions of $20 \%$ and $15.4 \%$ were found in two subjects after inhalation of weevil extract. In one case wheezing and cough developed. The changes in F.E.V.1.0 were reversed after inhalation of a bronchodilator aerosol.

Twenty-five of the control subjects with positive skin responses to the grain weevil were given similar provocation inhalations but none showed any significant change in F.E.V.1.0.

This pilot study suggests that grain weevil sensitivity is an additional factor in millworkers' asthma.

For centuries it has been observed that chest illness is common among bakers and flour millers. At the beginning of the eighteenth century Ramazzini (I7I3) observed that granary workers and millers developed shortness of breath with morning cough and expectoration. Until the beginning of this century it was generally assumed that the chest conditions were caused by the mechanical irritation of the mill dust. At that time, however, the allergic nature of these respiratory symptoms in millworkers began to be recognized. In 1935 Duke described four cases of bronchial asthma among flour millworkers in which the allergen was derived from the wheat grain. It became generally recognized that millers' asthma was an allergic response to one or several of the grain proteins. Further work indicated that other allergens were responsible, and, in discussing the nature of mill dust allergens, Wittich (1940) showed that grain smuts and grain

Received for publication September 9, 1965. rust, in addition to grain or flour mites, could cause hay fever or asthma. (Wittich also reported a case of allergic rhinitis and asthma caused by the bean weevil.)

A further possibility was suggested when two laboratory workers, who were exposed almost daily to the grain weevil (Sitophilus granarius), developed an allergic response which varied from rhinitis and pruritus to marked asthma (Frankland and Lunn, 1965). A similar response in a Spanish farmworker had been reported by Jimenez-Diaz, Lahoz, and Canto (1947). In this instance the worker had been packing grossly infested grain in preparation for sowing.

In view of these established cases of grain weevil sensitivity, it was considered that, if mill dust became contaminated by the grain weevil, it would be possible for those exposed to develop an allergic response. It was therefore decided to undertake a pilot study to determine whether cases of grain weevil sensitivity existed among millworkers. 


\section{Prevalence of the Grain Weevil}

The majority of mills in this country obtain grain from many overseas sources, virtually none of which is guaranteed to be free from weevil contamination. Supplies from the South American continent are particularly prone to contain the weevil. Some grain is stored for up to a year and during this time further breeding may occur. Apart from whole weevil and weevil dust the larval phase of the insect within the grain will also cause mill contamination. Except by laboratory methods, it is virtually impossible to detect and exclude the larval phase of the insect in the grain. A more detailed account of the grain weevil's life cycle is contained in the Ministry of Agriculture, Fisheries and Food (1962) Advisory Leaflet 219.

\section{Investigation}

To detect very small traces of foreign protein in dust samples highly specific and sensitive serological methods are necessary. These methods were not available for this study, but Venkat Rao, Krishnamurthy, Swaminathan, and Subrahmanyan (1959) have shown that uric acid, which is the main nitrogenous constituent of insect excreta, can serve as a sensitive index of insect infestation. Although it is not species specific, it is generally considered by those familiar with grain infestation that Sitophilus granarius is the most likely contaminant. The uric acid content of various samples of mill dust was estimated by the method used by Venkat Rao and his colleagues. Clean flour samples tested contained not more than I mg./100 g., and Table I gives values for different parts of one mill and clearly indicates insect contamination.

Skin Testing It was decided to skin test a group of millworkers against extracts of grain weevil and mixed flour, using the solvent ${ }^{\star}$ as a control. Volunteers were invited from three mills in the East End of London with a total population of about 400 , and those workers who suffered from shortness of breath, cough or chest tightness when working in the mill were especially encouraged to take part. Seventy-five volunteered. In addition to the skin tests, each volunteer was asked about chest tight-

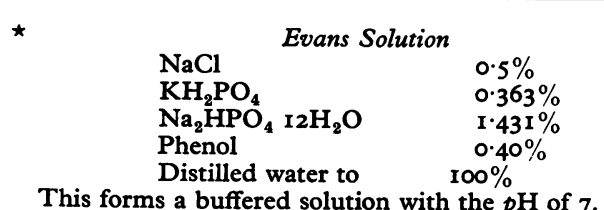

This forms a buffered solution with the $p H$ of 7 .
TABLE I

Uric Acid Values for SAmples of Mill Dust from ONe MILL

\begin{tabular}{lc} 
Source & Uric Acid $(\mathrm{mg} . / \mathrm{ro0} \mathrm{g.)}$ \\
\hline Receiving house & 27.9 \\
Tailing grinder & $44 \cdot 2$ \\
Wheat feed & 13.9 \\
Grinders & $149 \cdot 5$ \\
Sweepings from oats and barley & $25 \cdot 0$ \\
Barley meal & 23.9 \\
General sweepings from mill & 64.0 \\
Pig meal & $19 \cdot 7$
\end{tabular}

ness, cough, shortness of breath, and wheezing when working at the mill, and any freedom from these chest symptoms when away from work. Enquiries were also made about personal and family histories of allergy and the length of time of exposure to mill dust.

The age of the millworkers ranged from 16 to 65 , the average age being 53 years. There were $7 \mathrm{r}$ men and four women. The length of exposure varied from one month to 45 years, the average being 25 years.

Approximately one third of the millworkers had a productive cough for more than three months in the year and stated that, if exposed to very heavy concentrations of mill dust, symptoms of chest tightness and sometimes wheezing developed. Some considered that these symptoms occurred occasionally when handling different batches of grain, regardless of the amount of dust produced. Nearly all considered that their chest symptoms were better after a fortnight's holiday away from their work although few felt they were any better at week-ends.

One hundred volunteers in comparable age groups from two engineering firms were asked to have the same series of skin tests. It was explained that the purpose of the tests was to compare the responses with those in workers in the milling industry. There was no selection because of known chest or allergic history. Examination of the medical histories of these volunteers did not suggest that there was any bias towards those with chest disease.

Method A I\% weevil extract, prepared from whole weevils killed by chloroform, and a $1 \%$ extract of mixed flour were prepared and the solvent was used as a control. The intradermal method with $0.02 \mathrm{ml}$. was employed, and the results were read after 15 minutes. Urticarial reactions $5 \mathrm{~mm}$. in diameter or over were taken as positive responses, provided there was no response from the control.

Lung Function Tests and Provocation Testing Those millworkers who had a positive 
skin response to Sitophilus granarius and whose clinical histories suggested that an allergic response rather than chronic bronchitis might be responsible for their chest conditions were selected for further study. Out of the initial 75,15 were selected. Their ages ranged from 33 to 64 years, the average age being 52 years. The length of time of exposure to mill dust ranged from nine to 40 years, with an average of 27 years.

Lung function measurements and provocation testing were carried out using the following solutions: (a) solvent; (b) $5 \%$ weevil extract; and (c) $5 \%$ mixed flour extract. The solutions were nebulized in a Wright nebulizer using oxygen at 3 litres per minute. They were inhaled through a mask for periods of 15 seconds, 2,5 , and 10 minutes, and before any inhalation and after each, measurements were made of vital capacity (V.C.) and F.E.V.1.0, using a Bernstein spirometer. Where there was any significant change in F.E.V.1.0 after weevil inhalation, mixed flour inhalations were carried out on another day.

These lung function studies were also carried out on 25 of the control group who had positive skin responses to the weevil.

\section{Results}

Of the 75 millworkers, $43(57 \%)$ had a positive skin response to the weevil extract and $51(68 \%)$ a positive response to the mixed flour extract. In the control group, $34 \%$ were positive to the weevil extract and $17 \%$ to mixed flour.

It has been shown that when a population has a high exposure to a common allergen a sub-clinical sensitivity, i.e., skin response, develops in over $60 \%$ (Milner, 1959). The findings of a positive rate of $57 \%$ in this group of millworkers is consistent with these findings and of there being a fairly constant exposure to weevil dust in the mills. The positive rate of $34 \%$ in non-millworkers cannot be fully explained, but it may indicate that traces of weevil protein reach the general population through flour and its products, but in nothing like the quantities met with in the mills. Atmospheric pollution may also produce sub-clinical sensitivities, and an investigation into a high incidence of asthma among students of the University of Minnesota revealed that the prevailing wind contained dust particles from nearby grain mills, and that outbreaks of asthma among the students were related to increased atmospheric pollution by grain dust (Cowan, Thompson, Paulus, and Mielke, 1963).

Lung Function Studies and Provocation Testing None of the 15 millworkers showed any change in V.C. and F.E.V $\cdot{ }_{1 \cdot 0}$ after inhalation of the solvent. A further 12 showed no change in these measurements after weevil and mixed flour inhalations. In three subjects, however, significant reductions of at least $14 \%$ were noted in the F.E.V. $\cdot_{1 \cdot 0}$ in one subject after weevil inhalation only, in another after both weevil and mixed flour inhalation, and in the third after inhalation of mixed flour only (Table II). In the subject in whom there was a response to the weevil extract only, there was also a subjective sensation of chest tightness and wheezing.

Each subject who reacted was given a bronchodilator (orciprenaline) from a metered aerosol. In each case the F.E.V $\cdot_{1 \cdot 0}$ was restored to within $3 \%$ of the control measurement.

All these subjects gave a clear history of cough and chest tightness when working in the mill, and of relief of these symptoms after week-ends and holidays.

None of the 25 control subjects with positive skin responses to the weevil showed any significant change in F.E.V.$_{1 \cdot 0}$ on provocation testing with weevil extract.

\section{Further Work}

This pilot study of the possibility of sensitivity to the grain weevil in millworkers has shown that allergic responses to this insect do occur, and that this response must be considered an additional cause of millworkers' asthma. However, it is not yet possible to say how commonly this condition occurs, and a survey of the whole working popula-

TABLE II

\begin{tabular}{|c|c|c|c|c|c|}
\hline \multirow[b]{2}{*}{ Subject } & \multicolumn{5}{|c|}{ Provocation Testing (io min. inhalation): Changes in F.E.V.1.0 in Sensitive Subjects } \\
\hline & $\begin{array}{l}\text { Initial } \\
\text { F.E.V.1・0 }\end{array}$ & $\begin{array}{l}\text { After } \\
\text { Solvent }\end{array}$ & $\begin{array}{l}5 \% \text { Weevil } \\
\text { Extract }\end{array}$ & $\begin{array}{l}\text { Mixed Flour } \\
\text { Extract }\end{array}$ & Orciprenaline \\
\hline $\mathbf{I}$ & $\mathbf{1}, 750$ & $\mathbf{I}, 750(0)$ & $1,400(20)$ & $1,700(2 \cdot 9)$ & $1,700(2 \cdot 9)$ \\
\hline 2 & 2,550 & $2,500(2)$ & (a) $2,150(15 \cdot 4)$ & (b) $2,200(14)$ & $\begin{array}{l}\text { (a) } 2,500(2) \\
\text { (b) } 2,550(0)\end{array}$ \\
\hline 3 & 3,400 & $3,400(0)$ & $3,300(3)$ & $2,700(21)$ & $3,500(3)$ \\
\hline
\end{tabular}

F.E.V. $\cdot_{1 \cdot 0}$ expressed in $\mathrm{ml}$. with $\%$ change in parenthesis. 
tion of a mill is being undertaken to determine the incidence. This survey will take the form of a detailed questionnaire on respiratory and allergic symptoms, followed by lung function studies on the workers after freedom from dust exposure at the week-end, and again after a week's exposure to mill dust. Any showing significant changes in the F.E.V. $\cdot_{1 \cdot 0}$ will be further studied with selective provocation testing and skin tests to separate any weevil from mixed flour or other sensitivities.

I would like to express thanks to the following: Dr. F. H. Milner, Beecham Research Laboratories, for preparing the weevil extracts; Dr. D. T. D. Hughes, of the London Hospital, for advice with the lung function investigations; and Dr. William Hunter and the management of Ranks, Hovis, McDougall Limited for their help and co-operation.

\section{REFERENCES}

Cowan, D. W., Thompson, H. J., Paulus, H. J., and Mielke, P. W. (1963). F. Air Pollut. Control Ass., 13, 546.

Duke, W. W. (1935). F. Amer. med. Ass., 105, 957.

Frankland, A. W., and Lunn, J. A. (1965). Brit. F. industr. Med., 22, 157.

Jimenez-Diaz, C., Lahoz, C., and Canto, G. (1947). Ann. Allergy, 5, 519.

Milner, F. H. (1959). Occupational Allergy Supplement, pp. 3-7. Stenfert Kroese N.V., Leiden.

Ministry of Agriculture, Fisheries and Food (1962). Grain weevil advisory leaflet 219.

Ramazzini, B. (I713). De Morbus Artificum Diatriba (Diseases of Workers). Translated by Wilmer Cave Wright, 1940. University of Chicago Press, Chicago.

Venkat Rao, S., Krishnamurthy, K., Swaminathan, M., and Subrahmanyan, V. (1959). Food Science, 8, 12.1.

Wittich, F. W. (1940). F.-Lancet, 60, 418. 